\title{
Influence of the Surface Layer when the CMT Process Is Used for Welding Steel Sheets Treated by Nitrooxidation
}

\author{
I. Michalec, M. Marônek
}

\begin{abstract}
Nitrooxidation is a non-conventional surface treatment method that can provide significantly improved mechanical properties as well as corrosion resistance. However, the surface layer is a major problem during the welding process, and welding specialists face many problems regarding the weldability of steel sheets. This paper deals with the properties of a nitrooxidized surface layer, and evaluates ways of welding steel sheets treated by nitrooxidation using a Cold Metal Transfer (CMT) process. The limited heat input and the controlled metal transfer, which are considered as the main advantage of the CMT process, have a negative impact on weld joint quality. An excessive amount of porosity is observed, probably due to the high content of nitrogen and oxygen in the surface layer of the material and the fast cooling rate of the weld pool.
\end{abstract}

Keywords: steel sheet, nitrooxidation, Cold Metal Transfer, porosity.

\section{Introduction}

Steel sheets with surface treatment are widely used, above all in the automotive industry. This research work is in response to a problem encountered in practical applications of this material. An investigation is made of a new surface treatment method that has a major effect on improving the surface properties of steel sheets, e.g. their corrosion resistance. Nitrooxidation in a fluidized bed is a non-conventional surface treatment method. This process consists of nitridation with subsequent oxidation. Nitrooxidation leads to a significant increase in corrosion resistance (up to level 10), and also an increase in mechanical properties, e.g. yield strength and tensile strength $(1,2$, $3)$.

The process of welding damages the surface layer, and it is necessary to find a way to minimize this damage. A pulse process is applied to limit the thermal input in arc welding, where there is periodic pulsation of the welding voltage and the welding current. The CMT process, an innovative welding method, can also be used. CMT is a revolutionary shortcircuit welding method, which works with digitallycontrolled short-circuit metal transfer in the welding arc. For the first time, this method integrates the wire motion into the welding process and into the overall control of the process. In this way, the, ther- mal input can be limited. This is a major advantage of this welding method $(1,4,5)$.

\begin{abstract}
Aims
Previous studies $(3,5,6)$ dealt with ways of welding steel sheets treated by nitrooxidation. Several defects were identified in most of the tested methods, e.g. spatter, porosity and weld bead irregularities. Only solid-state laser beam welding was considered satisfactory. Because of the high initial cost of laser equipment, our research focused on finding an adequate option in field of arc welding. The main aim of the research was to evaluate the possibility of welding nitrooxidized material using the innovative CMT welding method.
\end{abstract}

\section{Materials and methods}

Thin DC 01/DIN EN 10130-9 steel sheets $1 \mathrm{~mm}$ in thickness were used in the experiments. The chemical composition of the steel is shown in Table 1. The material was subjected to the nitrooxidation process. A fluid environment consisting of $\mathrm{Al}_{2} \mathrm{O}_{3}$ grains $120 \mu \mathrm{m}$ in diameter was used in the nitridation treatment. The oxidation process was carried out in vapours of distilled water immediately after nitridation. The nitrooxidation treatment parameters are presented in Table 2.

Table 1: Chemical composition of DC 01 EN 10130/91 steel

\begin{tabular}{|c|c|c|c|c|c|c|}
\hline $\begin{array}{c}\text { EN } \\
\text { designation }\end{array}$ & $\begin{array}{c}\mathrm{C} \\
{[\%]}\end{array}$ & $\begin{array}{c}\mathrm{Mn} \\
{[\%]}\end{array}$ & $\begin{array}{c}\mathrm{P} \\
{[\%]}\end{array}$ & $\begin{array}{c}\mathrm{S} \\
{[\%]}\end{array}$ & $\begin{array}{c}\mathrm{Si} \\
{[\%]}\end{array}$ & $\begin{array}{c}\mathrm{Al} \\
{[\%]}\end{array}$ \\
\hline DC 01 & max. 0.10 & max. 0.45 & max. 0.03 & max. 0.03 & 0.01 & - \\
\hline
\end{tabular}


Table 2: The nitrooxidation parameters

\begin{tabular}{|l|c|c|}
\cline { 2 - 3 } \multicolumn{1}{c|}{} & $\begin{array}{c}\text { Temperature } T \\
{\left[{ }^{\circ} \mathrm{C}\right]}\end{array}$ & $\begin{array}{c}\text { Time } t \\
{[\mathrm{~min}]}\end{array}$ \\
\hline Nitridation & 580 & 45 \\
\hline Oxidation & 350 & 5 \\
\hline
\end{tabular}

Table 3: The chemical composition of OK AristoRod 12.50

\begin{tabular}{|c|c|c|}
\hline $\begin{array}{c}\mathrm{C} \\
{[\%]}\end{array}$ & $\begin{array}{c}\mathrm{Si} \\
{[\%]}\end{array}$ & $\begin{array}{c}\mathrm{Mn} \\
{[\%]}\end{array}$ \\
\hline 0.10 & 0.90 & 1.50 \\
\hline
\end{tabular}

The experiments were performed at Fronius Ltd., Trnava. The welding process configuration is shown in Figure 1. Robotised CMT welding was used. A total of 26 specimens with dimensions of $25 \times 10 \times 1 \mathrm{~mm}$ were produced. The welding parameters are presented in Table 4. I joints, overlapped joints and flange joints were welded. OK AristoRod 12.50, $1 \mathrm{~mm}$ in diameter, was used as the filler metal. CORGON 18 ( $18 \%$ of $\mathrm{CO}_{2}, 82 \%$ of Argon) with flow rate $15 \mathrm{l} \cdot \mathrm{min}^{-1}$ was applied as the shielding gas. The chemical composition of the filler metal is shown in Table 3 .

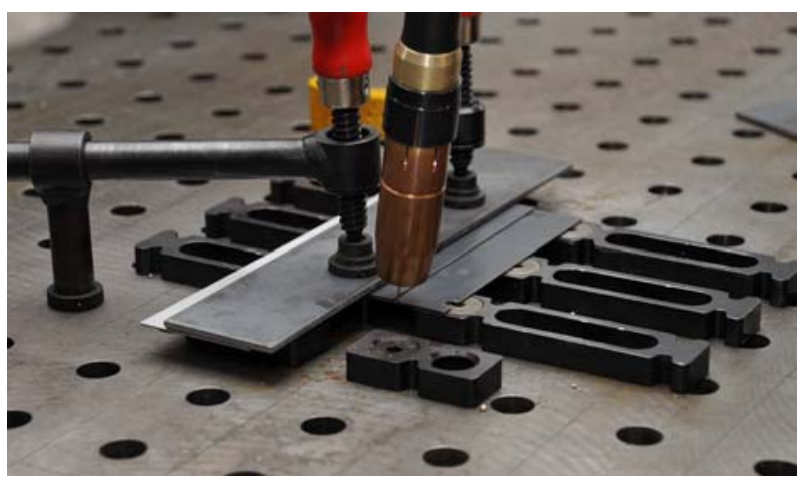

Fig. 1: Welding process configuration

Table 4: Welding parameters of the specimens

\begin{tabular}{|c|c|c|c|c|c|c|}
\hline $\begin{array}{c}\text { Specimen } \\
\text { No. }\end{array}$ & $\begin{array}{c}\text { Welding } \\
\text { current } \\
{[\mathrm{A}]}\end{array}$ & $\begin{array}{c}\text { Welding } \\
\text { voltage } \\
{[\mathrm{V}]}\end{array}$ & $\begin{array}{c}\text { Wire } \\
\text { feed rate } \\
{\left[\mathrm{m} \cdot \min ^{-1}\right]}\end{array}$ & $\begin{array}{l}\text { Welding } \\
\text { speed } \\
{\left[\mathrm{mm} \cdot \mathrm{s}^{-1}\right]}\end{array}$ & $\begin{array}{l}\text { Shielding } \\
\text { gas }\end{array}$ & $\begin{array}{l}\text { Filler } \\
\text { metal }\end{array}$ \\
\hline 1 & 92 & 10.1 & 3.6 & 7 & Corgon 18 & OK 12.50 \\
\hline 2 & 92 & 10.1 & 3.6 & 7 & Corgon18 & OK 12.50 \\
\hline 3 & 81 & 11.3 & 3.9 & 7 & Corgon18 & OK 12.50 \\
\hline 4 & 90 & 11.4 & 3.6 & 20 & Corgon 18 & OK 12.50 \\
\hline 5 & 89 & 10.4 & 3.6 & 33 & Corgon18 & OK 12.50 \\
\hline 6 & 90 & 10.1 & 3.7 & 10 & Corgon18 & OK 12.50 \\
\hline 7 & 88 & 9.0 & 5.3 & 20 & Corgon 18 & OK 12.50 \\
\hline 8 & 88 & 9.0 & 5.3 & 20 & Corgon18 & OK 12.50 \\
\hline 9 & 88 & 9.0 & 5.3 & 20 & Corgon 18 & OK 12.50 \\
\hline 10 & 92 & 10.1 & 3.6 & 7 & Corgon18 & OK 12.50 \\
\hline 11 & 92 & 10.1 & 3.6 & 7 & Corgon18 & OK 12.50 \\
\hline 12 & 81 & 11.3 & 3.9 & 7 & Corgon 18 & OK 12.50 \\
\hline 13 & 90 & 11.4 & 3.6 & 20 & Corgon18 & OK 12.50 \\
\hline 14 & 89 & 10.4 & 3.6 & 33 & Corgon18 & OK 12.50 \\
\hline 15 & 90 & 10.1 & 3.7 & 10 & Corgon18 & OK 12.50 \\
\hline 16 & 98 & 12.8 & 5.0 & 20 & Corgon18 & OK 12.50 \\
\hline 17 & 86 & 9.0 & 5.2 & 20 & Corgon18 & OK 12.50 \\
\hline 18 & 94 & 9.3 & 5.5 & 20 & Corgon 18 & OK 12.50 \\
\hline 19 & 103 & 9.8 & 6.0 & 20 & Corgon18 & OK 12.50 \\
\hline 20 & 103 & 9.8 & 6.0 & 20 & Corgon18 & OK 12.50 \\
\hline 21 & 107 & 10.9 & 4.5 & 20 & Corgon 18 & OK 12.50 \\
\hline 22 & 120 & 11.5 & 5.0 & 20 & Corgon18 & OK 12.50 \\
\hline 23 & 158 & 11.1 & 5.0 & 20 & Corgon18 & OK 12.50 \\
\hline 24 & 107 & 10.9 & 4.5 & 25 & Corgon 18 & OK 12.50 \\
\hline 25 & 179 & 12.2 & 6.0 & 20 & Corgon18 & OK 12.50 \\
\hline 26 & 158 & 11.1 & 5.0 & 20 & Corgon18 & OK 12.50 \\
\hline
\end{tabular}


The evaluation of the material and of the specimens was performed at the Faculty of Materials Science and Technology in Trnava. Microscopic analysis, spectroscopy and microhardness measurements were performed as an analysis of the material properties. Macroscopic analysis, microscopic analysis and microhardness measurements were performed for an evaluation of the joints.

GD-OES - QDP (Glow Discharge - Optical Emission Spectroscopy - Quantitative Depth Profiling) was performed with the following process parameters: the current was $15 \mathrm{~mA}$ at voltage $1000 \mathrm{~V}$. The analysis was performed on a nitrooxidized material and also on a material without surface treatment.

Vickers microhardness measurements were performed using Buehler IndentaMet 1100 Series equipment. The load force applied to the specimen was $981 \mathrm{mN}$, and the loading time was $10 \mathrm{~s}$. The measurements were carried out on nitrooxidized and nonnitrooxidized steel sheets $1 \mathrm{~mm}$ in thickness. The measurements were made transversely to the material thickness (from top to bottom), and were repeated on three separate specimens (nitrooxidized and without nitrooxidation) in order to obtain average values. The distance between the indents was $80 \mu \mathrm{m}$, and the depth of the first indent beneath the surface was $60 \mu \mathrm{m}$.

\section{Results}

\section{Material analysis}

The microstructure of the DC 01 steel after the nitrooxidation process is shown in Figure 2. Beneath the very thin oxide layer (up to $680 \mathrm{~nm}$ ), an $\varepsilon$-phase 7-10 $\mu \mathrm{m}$ in thickness was observed. It was composed of $\mathrm{Fe}_{2-3} \mathrm{~N}$. A compound layer was created under the $\varepsilon$-phase. It consisted of ferritic matrix with needleshaped $\gamma^{\prime}-\mathrm{Fe}_{4} \mathrm{~N}$ nitrides. The compound layer was approximately $200 \mu \mathrm{m}$ in thickness. These phases were identified by scanning electron microscopy, using a JEOL 7600-F scanning electron microscope.

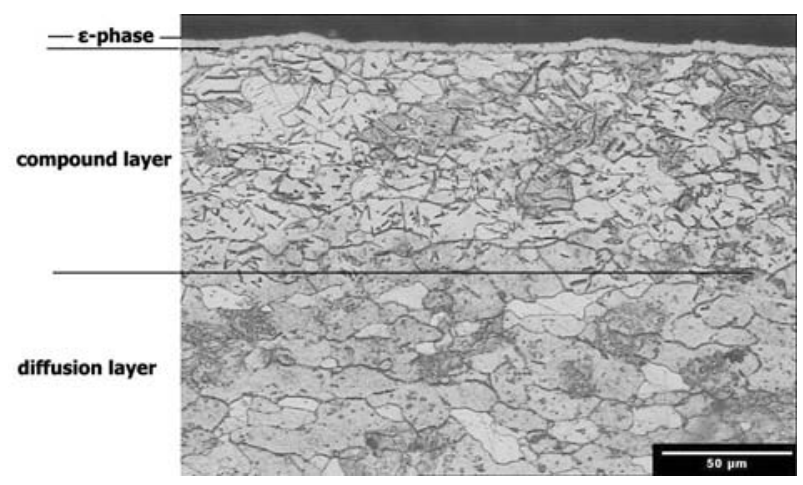

Fig. 2: Microstructure of the DC 01 steel after nitrooxidation

The results of the GD-OES analysis (Figure 3) showed that, after the nitrooxidation process, the nitrogen content had increased up to five times in the material surface. This increase was mainly at the expense of the iron content. The oxygen content at a depth of $1 \mu \mathrm{m}$ was more than $50 \%$ greater. This corresponds with the microscopic analysis, where an oxide surface layer $680 \mathrm{~nm}$ in thickness was observed.
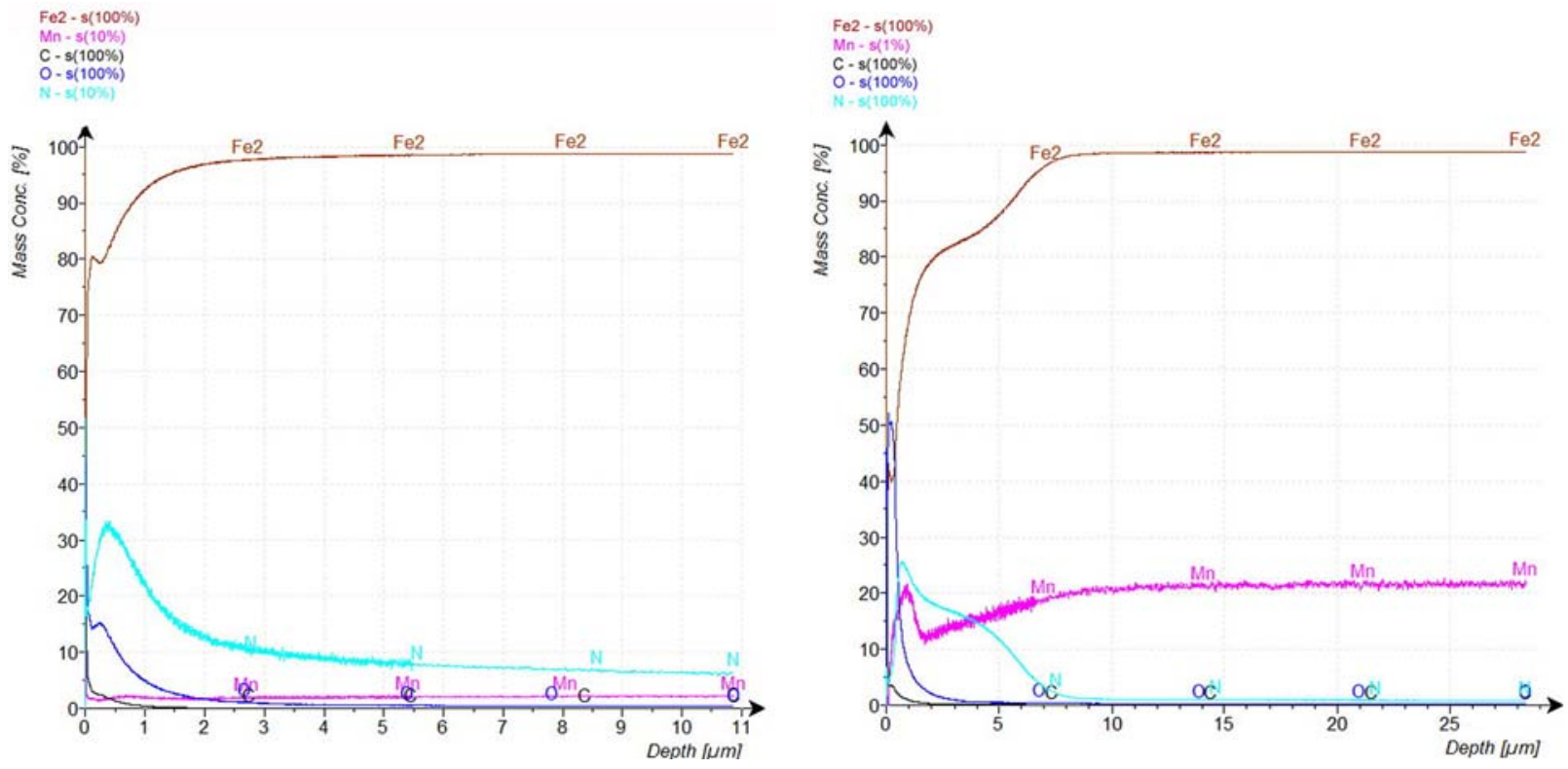

Fig. 3: GD-OES analysis of the material surface a) material without nitrooxidation b) material after nitrooxidation 


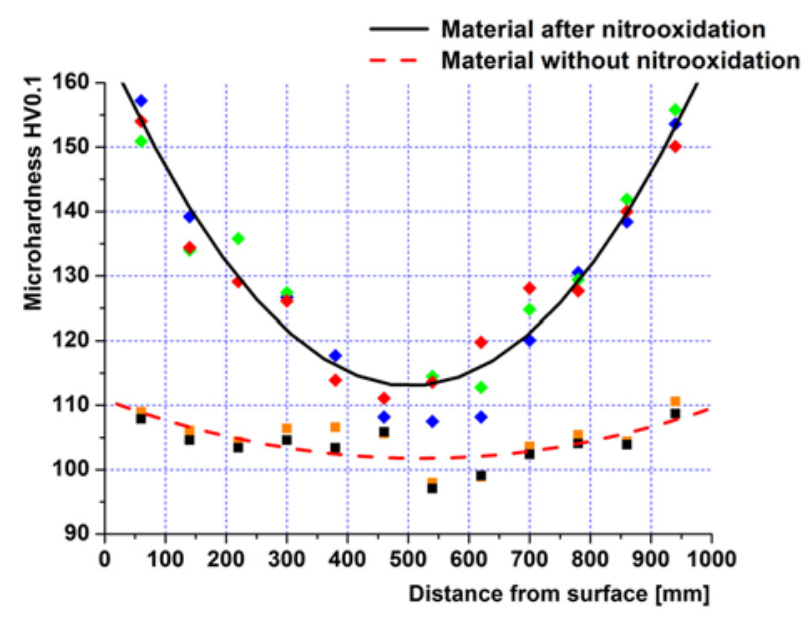

Fig. 4: Microhardness trend comparison of nitrooxidized material (black) and material without surface treatment (red)

The results of the microhardness measurements are shown in Figure 4. The graph compares the microhardness of the nitrooxidized material with the microhardness of the material without surface treatment. It can be observed that, after the nitrooxidation process, the material is affected to a depth of $400 \mu \mathrm{m}$. The highest microhardness values were observed on both surfaces of the steel sheet (distances 0 and $1000 \mu \mathrm{m}$ in the graph). They were $47 \%$ higher than the values for the material without surface treatment.

Due to limitations of the testing device, the microhardness values in the area of the $\varepsilon$-phase, where much higher values were expected (4), could not be observed.

\section{Analysis of the joints:}

Inappropriate joints were rejected in a visual inspection. Several defects, e.g. weld bead irregularity and weld bead reinforcement were detected. Only specimens with the minimum amount of defects were analysed.

The macroscopic analysis results are presented in Figure 5. The picture shows an excessive amount of porosity, distributed over almost the full length of the joint. Weld bead irregularity together with lack of fusion was also detected. The probable reason for the high porosity lies in the surface layer, which is rich in nitrogen and oxygen. However, the fast cooling rate may also have caused increased porosity, due to insufficient time for the escape of gases originating in the nitrooxidized surface layer and dissolved in WM during its melting process. These are until now just hypotheses, and will be a topic for further research.

The microscopic analysis results are shown in Figure 6. The Weld Metal (WM - see Figure 6a) was mainly composed of acicular ferrite. Globular ferrite was observed along the column grain boundaries. Widmanstätten ferrite was also observed sporadically. Figure $6 \mathrm{~b}$ shows the interface between the High Temperature Heat Affected Zone (HTHAZ) and WM. HTHAZ consisted of upper bainite, in which the $\mathrm{Fe}_{3} \mathrm{C}$ needles were secreted, together with coarse-grained acicular ferrite and proeutectoid ferrite. Coarsening of the primary austenitic grains was also identified. The Heat Affected Zone (HAZ - see Figure 6c) was composed of a fine-grained structure consisting of globular ferrite.
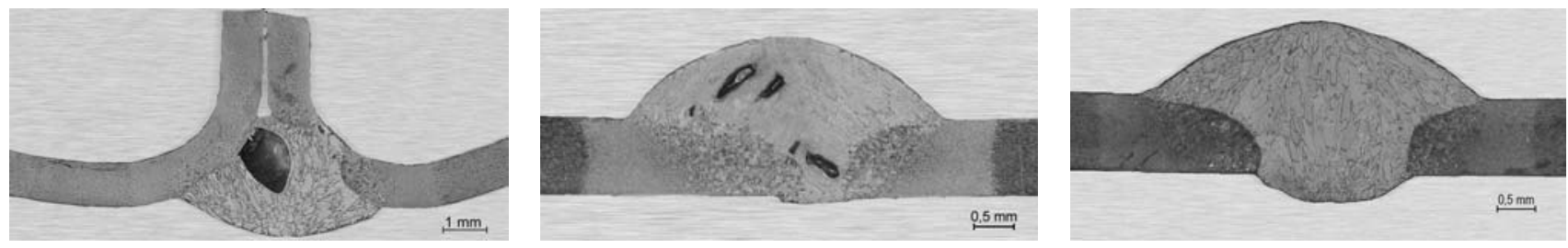

Fig. 5: Macrostructure of the joints
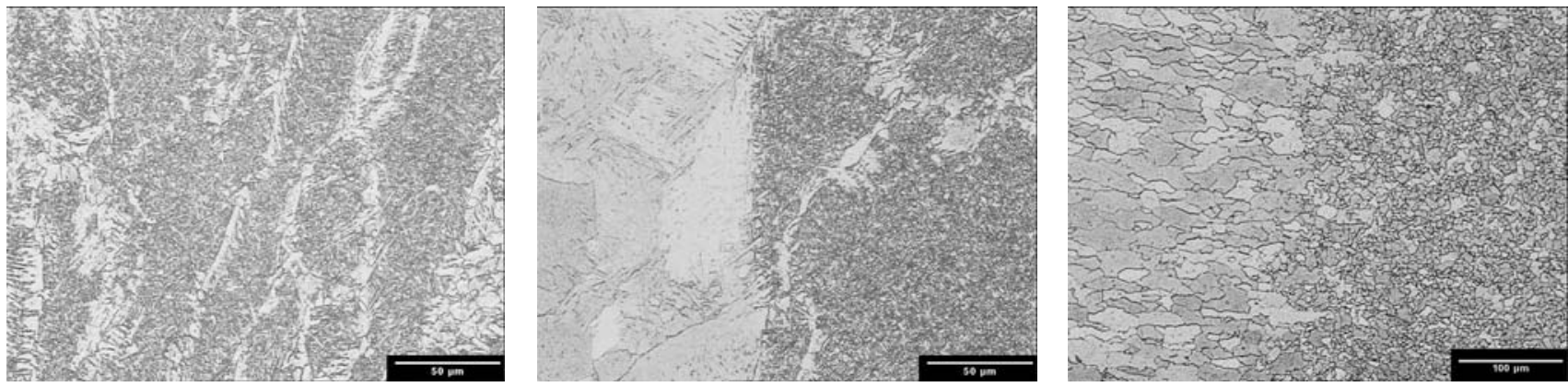

Fig. 6: Microstructure of the joints a) WM area b) WM - HTHAZ interface c) HAZ - BM interface 


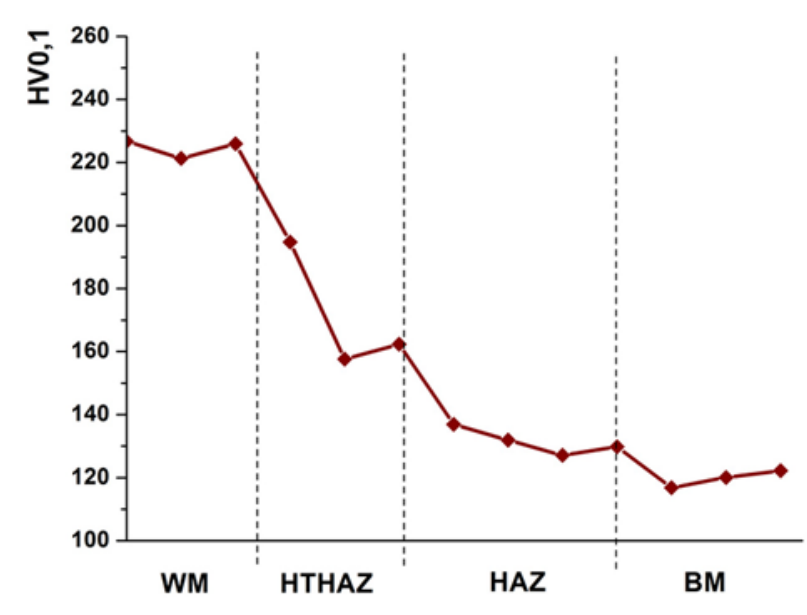

Fig. 7: Microhardness values trend

The results of the microhardness measurements (Figure 7) proved that the highest microhardness values were detected in WM. A continuous drop in microhardness was identified towards HAZ. In the area of BM, the microhardness stabilized, because there was no thermal affection within this area. The results presented here correspond with the microscopic analysis, where acicular ferrite was observed in the WM area.

\section{Conclusion}

The results show that for steel sheets treated by nitrooxidation there was a radical increase in microhardness values, up to $47 \%$, in comparison with the values for the same material without surface treatment. Microscopic analysis identified individual surface phases of the material treated by nitrooxidation. On the basis of the research results presented here, it can be stated that the given parameters of the CMT process were not suitable for welding steel sheets treated by nitrooxidation, due to the high level of porosity. Future research will focus on changing the shielding gas and the filler metal, and on optimizing the parameters.

\section{Acknowledgement}

This paper was prepared with support from the Slovak Research and Development Agency, grant No. 0057-07 and from the Scientific Grant Agency, grant No. 1/0203/11.

\section{References}

[1] Michalec, I.: CMT Technology Exploitation for Welding of Steel Sheets Treated by Nitrooxidation. Master's thesis, 2010.

[2] Michalec, I. et al.: Metallurgical joining of steel sheets treated by nitrooxidation by a hybrid CMT - laser process. In Metal 2011 - 20th Anniversary International Conference on Metallurgy and Materials, Brno : Tanger, 2011.

[3] Marônek, M. et al.: Welding of steel sheets treated by nitrooxidation, In JOM-16: 16th International Conference on the Joining of Materials \&f 7th International Conference on Education in Welding ICEW-7, Tisvildeleje, 2011.

[4] Dománková, M. et al: Influence of nitridation and nitrooxidation processes on microstructure and corrosion properties of low carbon deep-drawing steels. In Materials Science and Technology [online]. Vol. 11, No. 1, 2011, p. 40-51.

[5] Bárta, J. et al.: Joining of thin steel sheets treated by nitrooxidation. In 15th seminar of ESAB: Proceedings of lectures of the 15 th $E S A B+M T F$ $S T U$ seminar in the scope of seminars about welding and weldability. Trnava : AlumniPress, 2011, p. 57-67.

[6] Jančár, J. et al.: Laser beam utilisation in welding of steel sheets treated by nitrooxidation. In Využití laseru v prưmyslu. Plzeň : 2011, p. 25-35.

Ivan Michalec

E-mail: ivan.michalec@stuba.sk

Materiálovotechnologická fakulta STU

Katedra zvárania

J. Bottu 25, 91724 Trnava

Milan Marônek

E-mail: milan.maronek@stuba.sk

Materiálovotechnologická fakulta STU

Katedra zvárania

J. Bottu 25, 91724 Trnava 